\title{
Targeting Intracellular Cholesterol is a Novel Therapeutic Strategy for Cancer Treatment
}

\author{
Chandi C Mandal ${ }^{1 *}$ and Md Mizanur Rahman²
}

${ }^{1}$ Department of Biochemistry, School of Life Sciences, Central University of Rajasthan, Rajasthan-305817, India

${ }^{2}$ Department of Medicine, University of Texas Health Science Center at San Antonio, San Antonio, Texas-78229, USA

\begin{abstract}
Substantial data from cell culture and animal studies evidence the preventive effect of statins, cholesterol lowering-drugs, in regulation of cancer cell proliferation and metastasis. Various clinical studies also support this correlation between use of statin and the reduction of cancer incidence. However, in some cases, statins have failed to decrease the risk of cancer. Since, instead of serum cholesterol, intracellular cholesterol may play a crucial role in the regulation of tumorigenesis and metastasis. The mechanism by which cholesterol is stored within cancer cells may differ among cancer types and also in different individuals. This paper discusses the molecular detail to speculate the statin-sensitive cancer. It also highlights that statins may work better as anticancer therapy if it is used with the combination of a specific microRNA (miR).
\end{abstract}

Keywords: Intracellular cholesterol; Serum cholesterol; Statins, Cancer growth; Metastasis; microRNA

Cancer continues to be the second highest leading cause of morbidity and mortality throughout the world and is associated with highest economic burden. Overall, this is a matter of grave concern and calls for active research for development of effective and economical treatment strategies to extend the overall survival and improve the quality of life of cancer patients. Since tumor metastasis cause $80 \%$ of cancer patient death, metastasis management and control constitute the key requirement to treat cancer patients.

Cancers are perhaps the most complicated diseases because of its genetic heterogeneity and complexity. Each cancer has a distinct type of genetic alteration, oncogenic signaling, metabolic features, and epigenetic changes which are responsible for tumorigenesis [15]. Moreover, one sub-population of tumor cells may have a specific type of genetic feature and pathophysiology, which differ highly from other subsets within the same tumor and tumor type. More recently, obesity, diabetes, and hypercholesterolemia are being considered as important risk factors for cancer [6-9]. Emerging data also show the involvement of high-glucose and high-cholesterol in rewiring of metabolic programming which augments the process of tumorigenesis [10-14]. For example, enhanced level of low-density lipoprotein (LDL)and high-density lipoprotein (HDL)-cholesterol was found in cancer patients [15]. However, the relationship between serum cholesterol and increased risk of cancer still remains obscure $[9,16]$. Therefore, instead of serum cholesterol, recent studies are focusing toward the key role of intracellular cholesterol in cancer progression and metastasis. For instance, accumulation of intracellular cholesterol was found to be more in tumor tissues [17-19]. Moreover, metastatic cancer cells contain a higher intracellular lipid droplets when compared to normal epithelial cells [20]. Experimental evidences also support the idea that the intracellular cholesterol positively influences proliferation, migration, and invasion of cancer cells [21,22]. This establishes a positive link between elevation of intracellular cholesterol and increased risk of tumorigenesis. But the mechanisms need to be elucidated. Elevated level of cholesterol-rich lipid rafts or microdomains which organize signaling molecule and transduce intracellular signaling within the cells, was found in the plasma membrane of cancer cells [23] and the depletion of cholesterol from these lipid rafts enhances apoptotic death of cancer cells and sensitivity to chemotherapy [24]. Literature also discusses the possibility that the lipid rafts containing high level of cholesterol and GPI-anchored alkaline phosphatase enzyme could be pinched out from the plasma membrane and may form matrix vesicles within cells [25]. These vesicles deposit calcium hydroxy appetite crystal in the extracellular surface, which results in microcalcification of breast cancer tissues [25,26]. Interestingly, microcalcification was also found in other cancers such as ovarian and prostate cancers. New emerging data show a positive association of microcalcification with the malignancy of cancer [27-29]. Thus, elevated level of cholesterol present in the microdomain may promote metastasis of cancers by increasing microcalcification. Recent report shows that 27-hydroxy cholesterol is synthesized from cholesterol within cancer cells, and it may increase breast cancer growth and metastasis, since 27-hydroxy cholesterol binds to estrogen receptor alpha to activate oncogenic estrogen signaling [30]. The expression of cytochrome p450 CYP27A1 enzyme which converts cholesterol to 27-hydroxy cholesterol was shown to be more in epithelial breast tumors, and its expression is positively associated with the tumor grade [31]. These studies highlight the mechanism by which cholesterol may aggravate cancer growth and metastasis in case of breast cancer. However, this mechanism might not be operative to other cancer types or estrogen receptor negative tumor cells. Therefore, further research is required to establish the basic mechanism of cholesterol-mediated cancer growth and metastasis.

Statins are often prescribed to patients for lowering serum cholesterol level. Apart from cardio protective role, statin may prevent osteoporosis by increasing osteoblast differentiation and/ or by decreasing osteoclast activity [32,33]. Statins are known to

*Corresponding author: Chandi C Mandal, Department of Biochemistry, School of Life Sciences, Central University of Rajasthan, $\mathrm{NH}-8$, Bandarsindri, Kishangarh-305817, Ajmer, Rajasthan, India, Tel: +919650569396; Fax: +911463238772; E-mail: chandicmandal@gmail.com

Received December 17, 2014; Accepted December 18, 2014; Published December 20, 2014

Citation: Mandal CC, Rahman MM (2014) Targeting Intracellular Cholesterol is a Novel Therapeutic Strategy for Cancer Treatment. J Cancer Sci Ther 6: 510-513. doi:10.4172/1948-5956.1000316

Copyright: () 2014 Mandal CC. This is an open-access article distributed under the terms of the Creative Commons Attribution License, which permits unrestricted use, distribution, and reproduction in any medium, provided the original author and source are credited. 
inhibit cholesterol biosynthesis by blocking the activity of 3-hydroxy 3-methylglutaryl COA reductase (HMGCR), the rate limiting enzyme of mevalonate pathway [34]. Many investigators including us have established a preventive role of statins in cancer growth of many cancer types including breast, prostate, and ovarian cancers, evidenced by cell culture and animal model experiments [35-38]. We and others have also recently documented the preventive effect of statin in cancer metastasis, as demonstrated in breast cancer cells induced metastatic mice model $[36,39]$. Moreover, various clinical studies also support this correlation between use of statin and the reduction of cancer incidence [40-42]. A case-control study of half a million patients had displayed a $48 \%$ reduction in renal cell carcinoma [43], and a significant reduction in hepatocellular and in esophageal cancer was observed $[44,45]$ in case of the statin users. However, systematic review of randomized trials had failed to show cancer risk reduction after statin use and showed contradictory findings, with increased incidence for certain cancers and reduced incidence for other types [46,47]. A recent study shows that statin use in Danish cancer patients is associated with reduced cancerrelated mortality for 13 cancer types [48], but several investigators have raised their arguments against this report $[49,50]$. This poses a big challenge to the researchers and it has become imperative to identify the reasons behind the inconsistent results of statin treatment.

The mechanism by which cholesterol is accumulated within tumor cells may vary among cancer types and also in different individuals of same cancer type. In general, acquisition of intracellular cholesterol is mainly carried out in three main ways $[17,20]$. Excessive accumulation of cholesterol within cells could be either due to increased LDLcholesterol internalization because of high expression of low density lipoprotein receptor (LDLR), and/or due to increased synthesis of cholesterol inside cancer cells because of high activity of HMGCR, and/or inhibition of cholesterol efflux due to deficiency or inactivation of ATP-binding cassette $(\mathrm{ABC})$ transporter proteins such as ABCA1 and ABCG1 $[17,20]$. For instance, abnormal expressions of LDLR and HMGCR have been found in many cancer types $[17,18]$. Moreover, reciprocal expressions of LDLR and HMGCR in cancer tissues have also been documented [22]. Thus, expression patterns of LDLR and HMGCR may vary between statin-sensitive cancers and statininsensitive cancers. Detailed molecular investigations of individual tumors could explain the reason for enrichment of intracellular cholesterol inside cancer cells.

\section{Therapeutic Aspects: Targeting Intracellular Cholesterol}

Accumulating evidences highlight that instead of statin alone, the combination of statin with other partner might serve a better function to prevent cancer growth and metastasis. Several investigators along with ours have shown that omega- 3 fatty acids (docosahexaenoic acid; DHA and ecosapentaenoic acid; EPA), active components of fish oil, prevent cancer growth and metastasis, evidenced by cell culture and animal experiments [19,51-53]. Clinical studies also document the preventive role of omega-3 fatty acids in cancer risk [14]. Omega-3 fatty acids lower serum triacyl glycerol (TAG) which promotes tumorigenesis. Beside these, omega-3 fatty acids also prevent cholesterol synthesis in tumor cells [54]. Moreover, omega-3 fatty acids especially DHA disorganize the lipid rafts of plasma membrane by displacing cholesterol molecules, and dampen the microdomain mediated signaling, which may prevent cholesterol-assisted tumorigenesis [55,56]. This seems that the combined therapy of omega-3 fatty acid might increase the effectiveness of statin in preventing cholesterol-induced cancer progression and/or metastasis.
In the last decade, many researchers have worked to establish the role of microRNA (miRNA) in cancer progression and metastasis [57]. Dysregulation ofmiRNAsnotonlyaffectsvariousphysiological functions but also promotes many pathological functions. In fact, some miRNAs [e.g., miR-122 (Clinicaltrials.gov number, NCT01200420), miR-34 (Clinicaltrials.gov number, NCT01829971)] are currently underway in clinical trials $[58,59]$. Thus, miRNA seems to be a promising therapy in near future. Recent evidences indicate the involvement of many miRNAs (e.g., miR-33a, miR-128, miR-145, miR-185, and miR-19b) in the regulation of cholesterol metabolism [60-63]. Moreover, forced expression of miR-33a in cell lines directly suppresses the expression of ABCA1, resulting in inhibition of cholesterol efflux, whereas antagomir of miR-33a (anti-miR, inhibitor) increases cholesterol efflux by increasing the expression of ABCA1. But the combination of statin with anti-miR-33a may not be good choice for cancer treatment, because statin treatment upregulates miR-33a expression, and moreover, miR33 inhibits cell proliferation and cell cycle progression by targeting CDK6 and cyclin D1 [60,64]. Similarly, overexpression of miR-128 upregulates sterol-regulatory element-binding protein 2 (SREBP2) which transcriptionally increases expressions of HMGCR and LDLR, and inhibits expressions of transporter ABCA1 and ABCG1 [61]. These studies have shown an enhancement of LDLR by overexpressing of this miRNA whereas inconsistent results were found in case of HMGCR. It was demonstrated that miR-128 expression increases cellular cholesterol. Nevertheless, anti-miR-128 could not be used as an anticancer therapy, since overexpression of miR-128 have been shown to inhibit functional activity of tumor suppressor protein p53 [65]. However, forced expression of miR-185 and miR-372 inhibits SREBP1 and SREBP2, and its downstream target HMGCR with concomitant decrease of proliferation, migration, and invasion of prostate cancer cells [62]. Recent findings also show that miR-19b inhibits transporter ABCA1 with a concomitant decrease of cholesterol efflux, and it also promotes tumor growth and metastasis by blocking p53 activity $[63,66]$. Altogether, these data herein, recapitulate that mimic of miR185 , miR-372 and antagomir of miR-19b could be good candidates for cancer therapy. Thus, such combination of statin with either miR-185, or miR-372, or anti-miR-19b may be proposed for better therapy to prevent cancer growth and metastasis.

In brief, this note just provides a concept, but extensive research is required to understand the molecular mechanism as to how cholesterol regulates cancer progression and metastasis, and to determine if these microRNAs and such combinations work better for anticancer therapy.

\section{Acknowledgments}

CCM is supported by UGC Start-UP-Grant [30-49/2014 (BSR)] and MMR is supported by NIH, NIA K01 (KAG034233A). Authors would like to thank Dr. Alo Nag, Department of Biochemistry, University of Delhi South Campus, Delhi, India and Dr. Asok Banerjee, Department of Biochemistry, University of Texas Health Science Center at San Antonio, Texas, USA for critical reading and constructive criticisms.

Author have declared no conflict of interest.

\section{References}

1. Hanahan D, Weinberg RA (2000) The hallmarks of cancer. Cell 100: 57-70.

2. Jones PA, Baylin SB (2007) The epigenomics of cancer. Cell 128: 683-692.

3. Lengauer C, Kinzler KW, Vogelstein B (1998) Genetic instabilities in human cancers. Nature 396: 643-649.

4. Rikova K, Guo A, Zeng Q, Possemato A, Yu J, et al. (2007) Global survey 
of phosphotyrosine signaling identifies oncogenic kinases in lung cancer. Cell 131: $1190-1203$

5. Zheng J (2012) Energy metabolism of cancer: Glycolysis versus oxidative phosphorylation (Review). Oncol Lett 4: 1151-1157.

6. Calle EE, Kaaks R (2004) Overweight, obesity and cancer: epidemiological evidence and proposed mechanisms. Nat Rev Cancer 4: 579-591.

7. Giovannucci E, Harlan DM, Archer MC, Bergenstal RM, Gapstur SM, et al. (2010) Diabetes and cancer: a consensus report. CA Cancer J Clin 60: 207221.

8. Carracedo A, Cantley LC, Pandolfi PP (2013) Cancer metabolism: fatty acid oxidation in the limelight. Nat Rev Cancer 13: 227-232.

9. Nelson ER, Chang CY, McDonnell DP (2014) Cholesterol and breast cancer pathophysiology. Trends Endocrinol Metab 25: 649-655.

10. Kiberstis PA (2013) Cholesterol and Cancer. Science Signaling 6: ec292.

11. Furuta $E$, Okuda $H$, Kobayashi A, Watabe K (2010) Metabolic genes in cancer: their roles in tumor progression and clinical implications. Biochim Biophys Acta 1805: $141-152$

12. DeBerardinis RJ, Lum JJ, Hatzivassiliou G, Thompson CB (2008) The biology of cancer: metabolic reprogramming fuels cell growth and proliferation. Cell Metab 7: 11-20.

13. Lee BH, Taylor MG, Robinet P, Smith JD, Schweitzer J, et al. (2013) Dysregulation of cholesterol homeostasis in human prostate cancer through loss of ABCA1. Cancer Res 73: 1211-1218.

14. Zheng JS, Hu XJ, Zhao YM, Yang J, Li D (2013) Intake of fish and marine n-3 polyunsaturated fatty acids and risk of breast cancer: meta-analysis of data from 21 independent prospective cohort studies. BMJ 346: f3706.

15. Laisupasin P, Thompat W, Sukarayodhin S, Sornprom A, Sudjaroen Y (2013) Comparison of Serum Lipid Profiles between Normal Controls and Breast Cancer Patients. J Lab Physicians 5: 38-41.

16. Danilo C, Frank PG (2012) Cholesterol and breast cancer development. Curr Opin Pharmacol 12: 677-682.

17. Smith B, Land $H$ (2012) Anticancer activity of the cholesterol exporter ABCA1 gene. Cell Rep 2: 580-590.

18. Dessi S, Batetta B, Pulisci D, Spano O, Anchisi C, et al. (1994) Cholestero content in tumor tissues is inversely associated with high-density lipoprotein cholesterol in serum in patients with gastrointestinal cancer. Cancer 73: 253258.

19. Mandal CC, Ghosh-Choudhury T, Dey N, Choudhury GG, Ghosh-Choudhury $\mathrm{N}(2012)$ miR-21 is targeted by omega-3 polyunsaturated fatty acid to regulate breast tumor CSF-1 expression. Carcinogenesis 33: 1897-1908.

20. Martin BJ, van Golen KL (2012) A comparison of cholesterol uptake and storage in inflammatory and noninflammatory breast cancer cells. Int J Breast Cancer 2012: 412581.

21. Llaverias G, Danilo C, Mercier I, Daumer K, Capozza F, et al. (2011) Role of cholesterol in the development and progression of breast cancer. Am J Pathol 178: $402-412$.

22. Notarnicola M, Messa C, Pricci M, Guerra V, Altomare DF, et al. (2004) Upregulation of 3-hydroxy-3-methylglutaryl coenzyme $A$ reductase activity in leftsided human colon cancer. Anticancer Res 24: 3837-3842.

23. Li YC, Park MJ, Ye SK, Kim CW, Kim YN (2006) Elevated levels of cholesterolrich lipid rafts in cancer cells are correlated with apoptosis sensitivity induced by cholesterol-depleting agents. Am J Pathol 168: 1107-1118.

24. Tiwary R, Yu W, deGraffenried LA, Sanders BG, Kline K (2011) Targeting cholesterol-rich microdomains to circumvent tamoxifen-resistant breast cancer. Breast Cancer Res 13: R120.

25. Golub EE (2009) Role of matrix vesicles in biomineralization. Biochim Biophys Acta 1790: 1592-1598.

26. Anderson HC (2003) Matrix vesicles and calcification. Curr Rheumatol Rep 5 : 222-226.

27. Haka AS, Shafer-Peltier KE, Fitzmaurice M, Crowe J, Dasari RR, et al. (2002) Identifying microcalcifications in benign and malignant breast lesions by probing differences in their chemical composition using Raman spectroscopy Cancer Res 62: 5375-5380.

28. Baker R, Rogers KD, Shepherd N, Stone N (2010) New relationships between breast microcalcifications and cancer. Br J Cancer 103: 1034-1039.

29. Scimeca M, Giannini E, Antonacci C, Pistolese CA, Spagnoli LG, et al. (2014) Microcalcifications in breast cancer: an active phenomenon mediated by epithelial cells with mesenchymal characteristics. BMC Cancer 14: 286.

30. Lubik AA, Gunter JH, Hendy SC, Locke JA, Adomat HH, et al. (2011) Insulin increases de novo steroidogenesis in prostate cancer cells. Cancer Res 71 5754-5764.

31. Nelson ER, Wardell SE, Jasper JS, Park S, Suchindran S, et al. (2013) 27-Hydroxycholesterol links hypercholesterolemia and breast cancer pathophysiology. Science 342: 1094-1098.

32. Mundy G, Garrett R, Harris S, Chan J, Chen D, et al. (1999) Stimulation of bone formation in vitro and in rodents by statins. Science 286: 1946-1949.

33. Ghosh-Choudhury N, Mandal CC, Choudhury GG (2007) Statin-induced Ras activation integrates the phosphatidylinositol 3-kinase signal to Akt and MAPK for bone morphogenetic protein-2 expression in osteoblast differentiation. J Biol Chem 282: 4983-4993

34. Istvan ES, Deisenhofer J (2001) Structural mechanism for statin inhibition of HMG-CoA reductase. Science 292: 1160-1164.

35. Ghosh-Choudhury N, Mandal CC, Ghosh-Choudhury N, Ghosh Choudhury G (2010) Simvastatin induces derepression of PTEN expression via NFkappaB to inhibit breast cancer cell growth. Cell Signal 22: 749-758.

36. Mandal CC, Ghosh-Choudhury N, Yoneda T, Choudhury GG, GhoshChoudhury N (2011) Simvastatin prevents skeletal metastasis of breast cancer by an antagonistic interplay between p53 and CD44. J Biol Chem 286: 11314 11327.

37. Park YH, Jung HH, Ahn JS, Im YH (2013) Statin induces inhibition of triple negative breast cancer (TNBC) cells via PI3K pathway. Biochem Biophys Res Commun 439: 275-279.

38. Bababeygy SR, Polevaya NV, Youssef S, Sun A, Xiong A, et al. (2009) HMGCoA reductase inhibition causes increased necrosis and apoptosis in an in vivo mouse glioblastoma multiforme model. Anticancer Res 29: 4901-4908.

39. Liu H, Wang Z, Li Y, Li W, Chen Y (2013) Simvastatin prevents proliferation and bone metastases of lung adenocarcinoma in vitro and in vivo. Neoplasma 60: $240-246$.

40. Cauley JA, Zmuda JM, Lui LY, Hillier TA, Ness RB, et al. (2003) Lipid-lowering drug use and breast cancer in older women: a prospective study. J Womens Health (Larchmt) 12: 749-756.

41. Hindler K, Cleeland CS, Rivera E, Collard CD (2006) The role of statins in cancer therapy. Oncologist 11: 306-315.

42. Shannon J, Tewoderos S, Garzotto M, Beer TM, Derenick R, et al. (2005) Statins and prostate cancer risk: a case-control study. Am J Epidemiol 162 318-325.

43. Khurana V, Caldito G, Ankem M (2008) Statins might reduce risk of renal cell carcinoma in humans: case-control study of 500,000 veterans. Urology 71 118-22.

44. Singh PP, Singh S (2012) Statins and risk reduction in hepatocellular carcinoma: fact or fiction? J Clin Oncol 30: 2569-2570.

45. Singh S, Singh PP, Singh AG, Murad MH, Sanchez W (2013) Statins are associated with a reduced risk of hepatocellular cancer: a systematic review and meta-analysis. Gastroenterology 144: 323-332.

46. Kuoppala J, Lamminpää A, Pukkala E (2008) Statins and cancer: A systematic review and meta-analysis. Eur J Cancer 44: 2122-2132.

47. Sacks FM, Pfeffer MA, Moye LA, Rouleau JL, Rutherford JD, et al. (1996) The effect of pravastatin on coronary events after myocardial infarction in patients with average cholesterol levels. Cholesterol and Recurrent Events Trial investigators. N Engl J Med 335: 1001-1009.

48. Nielsen SF, Nordestgaard BG, Bojesen SE (2012) Statin use and reduced cancer-related mortality. N Engl J Med 367: 1792-1802.

49. Dawwas MF (2013) Statin use and reduced cancer-related mortality. N Engl J Med 368: 574-575.

50. Klop C, Driessen JH, de Vries F (2013) Statin use and reduced cancer-related 
Citation: Mandal CC, Rahman MM (2014) Targeting Intracellular Cholesterol is a Novel Therapeutic Strategy for Cancer Treatment. J Cancer Sci Ther 6: 510-513. doi:10.4172/1948-5956.1000316

mortality. N Engl J Med 368: 574.

51. Ghosh-Choudhury T, Mandal CC, Woodruff K, St Clair P, Fernandes G, et al. (2009) Fish oil targets PTEN to regulate NFkappaB for downregulation of antiapoptotic genes in breast tumor growth. Breast Cancer Res Treat 118: 213228.

52. Mandal CC, Ghosh-Choudhury T, Yoneda T, Choudhury GG, GhoshChoudhury N (2010) Fish oil prevents breast cancer cell metastasis to bone. Biochem Biophys Res Commun 402: 602-607.

53. Rahman MM, Veigas JM, Williams PJ, Fernandes G (2013) DHA is a more potent inhibitor of breast cancer metastasis to bone and related osteolysis than EPA. Breast Cancer Res Treat 141: 341-352.

54. Gelsomino G, Corsetto PA, Campia I, Montorfano G, Kopecka J, et al. (2013) Omega 3 fatty acids chemosensitize multidrug resistant colon cancer cells by down-regulating cholesterol synthesis and altering detergent resistant membranes composition. Mol Cancer 12: 137.

55. Corsetto PA, Cremona A, Montorfano G, Jovenitti IE, Orsini F, et al. (2012) Chemical-physical changes in cell membrane microdomains of breast cancer cells after omega-3 PUFA incorporation. Cell Biochem Biophys 64: 45-59.

56. Shaikh SR (2012) Biophysical and biochemical mechanisms by which dietary $\mathrm{N}-3$ polyunsaturated fatty acids from fish oil disrupt membrane lipid rafts. J Nut Biochem 23: 101-105.

57. Mendell JT, Olson EN (2012) MicroRNAs in stress signaling and human disease. Cell 148: 1172-1187.

58. Nana-Sinkam SP, Croce CM (2013) Clinical applications for microRNAs in cancer. Clin Pharmacol Ther 93: 98-104.

59. Janssen HL, Reesink HW, Lawitz EJ, Zeuzem S, Rodriguez-Torres M, et al.
(2013) Treatment of HCV infection by targeting microRNA. N Engl J Med 368: 1685-1694.

60. Najafi-Shoushtari SH, Kristo F, Li Y, Shioda T, Cohen DE, et al. (2010) MicroRNA-33 and the SREBP host genes cooperate to control cholesterol homeostasis. Science 328: 1566-1569.

61. Adlakha YK, Khanna S, Singh R, Singh VP, Agrawal A, et al. (2013) Proapoptotic miRNA-128-2 modulates ABCA, ABCG1 and RXRÎt expression and cholesterol homeostasis. Cell Death Dis 4: e780.

62. Li X, Chen YT, Josson S, Mukhopadhyay NK, Kim J, et al. (2013) MicroRNA-185 and 342 inhibit tumorigenicity and induce apoptosis through blockade of the SREBP metabolic pathway in prostate cancer cells. PLoS One 8: e70987.

63. Lv YC, Tang YY, Peng J, Zhao GJ, Yang J, et al. (2014) MicroRNA-19b promotes macrophage cholesterol accumulation and aortic atherosclerosis by targeting ATP-binding cassette transporter A1. Atherosclerosis 236: 215-226.

64. Cirera-Salinas D, Pauta M, Allen RM, Salerno AG, Ramírez CM, et al. (2012) Mir-33 regulates cell proliferation and cell cycle progression. Cell Cycle 11: 922-933.

65. Adlakha YK, Saini N (2013) miR-128 exerts pro-apoptotic effect in a p53 transcription-dependent and -independent manner via PUMA-Bak axis. Cell Death Dis 4: e542.

66. Fan Y, Yin S, Hao Y, Yang J, Zhang H, et al. (2014) miR-19b promotes tumor growth and metastasis via targeting TP53. RNA 20: 765-772. 